\title{
The half-turned truncal switch operation adds a new spin for patients with complex coronary anatomy and transposition of the great arteries
}

\author{
Travis J. Wilder, MD
}

From the Department of Surgery, University of California San Diego, San Diego, Calif.

Disclosures: Author has nothing to disclose with regard to commercial support.

Received for publication March 5, 2017; accepted for publication March 10, 2017; available ahead of print April $12,2017$.

Address for reprints: Travis J. Wilder, MD, University of California San Diego, 200 W Arbor Drive, \#8220,

San Diego, CA 92103 (E-mail: twilder@ucsd.edu).

J Thorac Cardiovasc Surg 2017;154:271-2

$0022-5223 / \$ 36.00$

Copyright (C) 2017 by The American Association for Thoracic Surgery

http://dx.doi.org/10.1016/j.jtcvs.2017.03.021

The half-turned truncal switch operation (HTTSO) was first reported by Yamagishi and colleagues ${ }^{1}$ in 2003 as an alternative to the Rastelli and Lecompte operations for patients with complete transposition of the great arteries (TGA) not amenable to standard arterial switch operations (Figure 1). As mentioned by Yamagishi and colleagues ${ }^{1}$ in their initial publication, the HTTSO was initially contraindicated for patients with TGA in combination with a complex anomalous coronary artery. Despite initial concerns, however, indications for the HTTSO have broadened to include patients with aberrant coronary artery anatomy. ${ }^{2}$

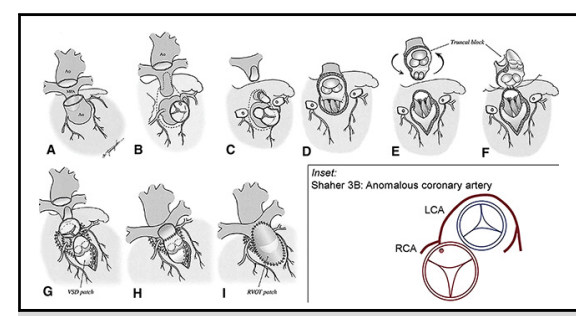

Original half-turned truncal switch operation. Shaher 3B coronary artery aberrancy (inset).

Central Message

The HTTSO is a viable option for patients with TGA and complex coronary artery anomalies.

See Article page 268.
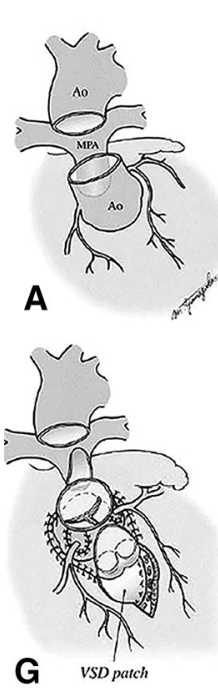

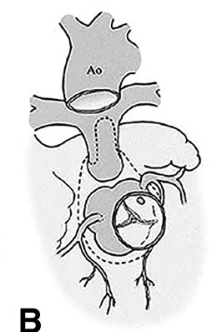

B
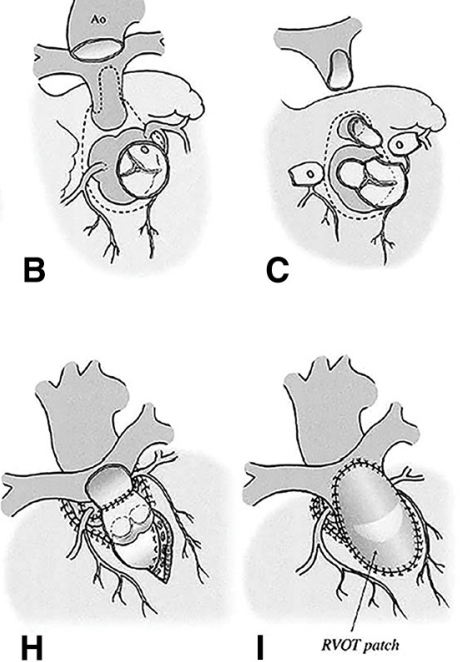

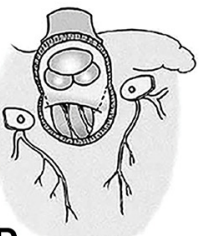

D

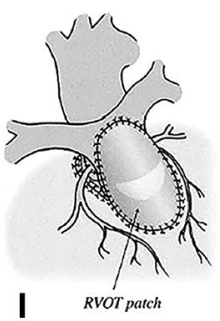

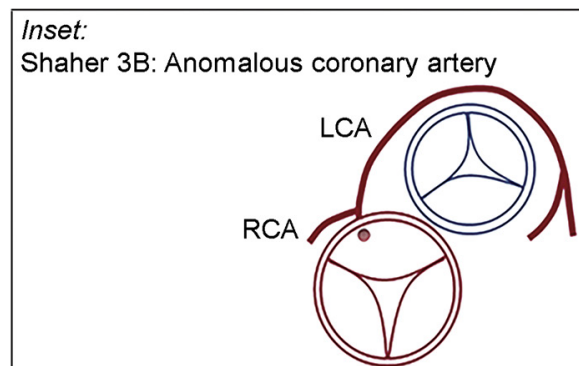

FIGURE 1. A, Anteriorly located aorta (Ao) transected above coronary orifices, with main pulmonary artery (MPA) located posteriorly. B, Anterosuperior view of truncal root. The incised line (dotted line) on the MPA runs obliquely from the posterior wall of the pulmonary annulus to anterior wall of pulmonary bifurcation. C, MPA incised obliquely with resection of both coronary arterial buttons. D, Anterior wall of the right ventricle was incised along the aortic annulus. Dotted line is incised line on infundibular septum. E, Fibrous continuity between the pulmonary valve and mitral valve incised. The truncal block for both semilunar valves is separated from ventricular outflow tract and truncal block is rotated one-half turn. F, Half-turned truncal block is anastomosed to left ventricular outflow orifice. G, Both coronary buttons anastomosed to corresponding aortic wall defect and ventricular septal defect (VSD) closed with ePTFE patch (VSD patch). H, Pulmonary bifurcation translocated anteriorly and ascending aorta reconstructed via end-to-end anastomosis. I, Right ventricular outflow tract covered with autologous pericardial patch (RVOT patch) equipped with monocuspid ePTFE valve. LCA, Left coronary artery; RCA, right coronary artery. Reprinted from Yamagishi and colleagues. ${ }^{1}$ 
In the current issue of the Journal, Nomura and colleagues ${ }^{3}$ present a case report describing the use of HTTSO for a child with TGA, double-outlet right ventricle, pulmonary stenosis, and an anomalous coronary artery with "high-risk" features. The specific aberrant coronary artery anatomy was a single anomalous artery arising from the right-facing sinus of Valsalva with an anterior traveling right coronary artery and a posteriorly traveling left coronary artery, coursing around the pulmonary trunk (Figure 1, inset).

It is not uncommon to find aberrant coronary artery anatomy in conjunction with TGA. In addition, some anomalies are considered to have higher-risk features and are associated with a higher rate of ischemic events after reimplantation. For example, an intramural coronary artery has been associated with a 5-fold increased risk of death versus normal coronary anatomy. ${ }^{4,5}$ Likewise, a coronary artery that arises from a single ostium and travels in a looping pattern has been associated with a 3-fold increased risk of death. $^{4}$ Although numerous reimplantation techniques have been described for a variety of defects, strong evidence-based repair strategies remain limited for complex anomalies. These limitations are, in part, related to the extensive anatomic variability and relatively limited experience of any one center. As such, unfavorable coronary artery anatomy remains a contraindication for switch operations at some institutions. ${ }^{5}$

Aberrant coronary arteries with a looping pattern have proved particularly difficult to reimplant during a switch operation. ${ }^{4,5}$ A coronary artery is considered to loop posteriorly if one or more major branches travels posteriorly around the pulmonary trunk, as was observed in the current case. A looping artery arising from single ostium may be at increased risk of kinking and distortion after reimplantation because of a shorter distance and acute turn between the neocoronary orifice and the coronary artery. ${ }^{5}$ Perhaps the most important determinate of a successful outcome after a switch operation is a tension- and torsion-free reimplantation of the coronary arteries. ${ }^{6}$ Therefore, it is not surprising to suggest that the favorable outcome of the current case was due to decreased distortion of the implanted coronary artery associated with HTTSO. Of note, the authors provide important insight for future surgeons, noting that a minimum distance of $3 \mathrm{~mm}$ between the looping left coronary artery and the pulmonary annulus may be needed to harvest the truncal block. ${ }^{3}$

Nomura and colleagues ${ }^{3}$ provide an excellent summary of an operation for a complex surgical problem. Although they are to be congratulated on their innovative technique, it is important to mention that the current report describes a single case, conducted at the hands of surgeons with a great deal of experience performing the HTTSO. Although the operation is enticing in the setting of a positive outcome, further experience will need to be gathered to direct clinical implications. Despite these imitations, the described modification of the HTTSO provides an additional technique to add to the armamentarium for congenital heart surgeons dealing with complex coronary artery anatomy.

\section{References}

1. Yamagishi M, Shuntoh K, Matsushita T, Fujiwara K, Shinkawa T, Miyazaki T, et al. Half-turned truncal switch operation for complete transposition of the great arteries with ventricular septal defect and pulmonary stenosis. J Thorac Cardiovasc Surg. 2003;125:966-8.

2. Mair R, Sames-Dolzer E, Innerhuber M, Tulzer A, Grohmann E, Tulzer G. Anatomic repair of complex transposition with en bloc rotation of the truncus arteriosus: 10-year experience. Eur J Cardiothorac Surg. 2016;49: 176-82.

3. Nomura K, Yamamoto M, Yamamoto Y, Ko Y. Half-turned truncal switch operation for single coronary in a patient with transposition of the great artery and pulmonary stenosis. J Thorac Cardiovasc Surg. 2017;154:268-70.

4. Pasquali SK, Hasselblad V, Li JS, Kong DF, Sanders SP. Coronary artery pattern and outcome of arterial switch operation for transposition of the great arteries: a meta-analysis. Circulation. 2002;106:2575-80.

5. Suzuki T. Modification of the arterial switch operation for transposition of the great arteries with complex coronary artery patterns. Gen Thorac Cardiovasc Surg. 2009;57:281-92.

6. Kim TH, Jung JJ, Kim YH, Yang JH, Jun TG. Technique of coronary transfer for TGA with single coronary artery. Korean J Thorac Cardiovasc Surg. 2014;47: 529-32. 